\title{
COMUNICAÇÃO
}

\section{QUANTIFICAÇÃO DE AÇÚCARES SOLÚVEIS TOTAIS, AÇÚCARES REDUTORES E ÁMIDO NOS GRÃOS VERDES DE CULTIVARES DE MILHO NA COLHEITA}

\author{
Quantification of total soluble sugars, reducing sugars and starch in \\ immature kernels of corn cultivars \\ Fernanda Fátima Caniato ${ }^{1}$, João Carlos Cardoso Galvão ${ }^{2}$, Fernando Luiz Finger ${ }^{3}$, Mário Puiatti ${ }^{4}$, \\ Denilson Alves de Oliveira ${ }^{5}$, Juliano Lino Ferreira ${ }^{6}$
}

\begin{abstract}
RESUMO
O objetivo deste trabalho foi quantificar os teores de açúcares solúveis totais (AST), açúcares redutores (AR) e amido em nove cultivares de milho colhidos no estádio verde, uma vez que estes influenciam diretamente o sabor, o aroma e a aceitação do consumidor. O experimento foi conduzido em Ponte Nova, MG, no ano agrícola 2002/2003. Para a determinação das características, foi retirada uma amostra de três espigas de cada unidade experimental. O ponto de colheita foi identificado por método empírico, quando o estilo-estigma se desprendia da espiga com facilidade. As cultivares apresentaram umidades diferentes no momento da colheita, variando de 56 a 64\%. Não foi detectada diferença entre as cultivares quanto aos teores de AR, porém, P3232 e AG4051 apresentaram boa relação entre AR e AST, destacando-se para esta finalidade.
\end{abstract}

Termos para indexação: Milho verde, composição química, carboidratos solúveis.

\section{ABSTRACT}

Total soluble sugars (TSS), reducing sugars (RS), moisture and starch directly influence flavor and consumption. In this work, TSS, RS and starch were determined at harvest in young kernels of nine corn cultivars. The experiment was carried out in Ponte Nova, MG, Brazil. To determine chemical characters of young kernels a sample was obtained of three cobs from each experimental plot. Corn ears were harvested using an empirical method, when the silk was loose from the ear. Moisture varied among samples of different cultivars at harvest. Moisture content ranged from 56 to $64 \%$. There were no differences among cultivars regarding RS. However, cultivars P3232 and AG4051 showed good RS to TSS ratio, being adequate for fresh consumption.

Index terms: Corn, chemical composition, soluble carbohydrates.

(Recebido em 22 de novembro de 2005 e aprovado em 4 de agosto de 2006)

O milho destaca-se entre os cereais mais produzidos no Brasil. Em 2004 a produção foi de 41.863 .756 milhões de toneladas, obtida em uma área de 12.410.340 milhões de hectares (FAO, 2002). No entanto, o cultivo visando o seu consumo na forma verde apresenta menor expressividade, segundo dados do Censo de 1995/96 (IBGE, 1996) o cultivo do milho verde ocupa apenas $0,85 \%$ da área cultivada com o milho com uma produtividade média de $2.855 \mathrm{~kg} / \mathrm{ha}$ de espigas verdes. Todavia, para os agricultores, o milho verde é uma fonte adicional de renda, pois este apresenta valor comercial superior ao milho comercializado na forma de grãos.

O mercado consumidor de milho verde tem se tornado cada vez mais exigente com relação à qualidade do produto. Características comumente usadas para descrever a qualidade do milho verde "in natura" incluem sanidade, aparência, como também características composicionais, que conferem ao milho sabor e aroma

\footnotetext{
'Engenheira Agrônoma, Doutoranda em Genética e Melhoramento - Departamento de Fitotecnia/DFT - Universidade Federal de Viçosa/UFV - Avenida PH Rolfs, s/n, Campus Universitário - 36570-000 - Viçosa, MG - fernandacaniato@yahoo.com.br

'Engenheiro Agrônomo, Professor Associado I-Departamento de Fitotecnia/DFT - Universidade Federal de Viçosa/UFV - Avenida PH Rolfs, s/n, Campus Universitário - 36570-000 - Viçosa, MG - jgalvao@ufv.br

${ }^{3}$ Engenheiro Agrônomo, Professor Associado I - Departamento de Fitotecnia/DFT - Universidade Federal de Viçosa/UFV - Avenida PH Rolfs, s/n, Campus Universitário - 36570-000 - Viçosa, MG - ffinger@ufv.br

${ }^{4}$ Engenheiro Agrônomo, Professor Associado I - Departamento de Fitotecnia/DFT - Universidade Federal de Viçosa/UFV - Avenida PH Rolfs, s/n, Campus Universitário - 36570-000 - Viçosa, MG - mpuiatti@ufv.br

${ }^{5}$ Engenheiro Agrônomo - Rua Cambuquira, 291, Nossa Senhora das Graças - 35700-493 - Sete Lagoas, MG - nideson@yahoo.com.br

${ }^{6}$ Engenheiro Agrônomo, Doutorando em Genética e Melhoramento - Departamento de Fitotecnia/DFT - Universidade Federal de Viçosa/UFV - Avenida

PH Rolfs, s/n, Campus Universitário - 36570-000 - Viçosa, MG - julianolf@yahoo.com.br
} 
característicos. Dentre estas, destacam-se concentração de amido, polissacarídeos solúveis em água, açúcares redutores e sacarose. Estas variam de acordo com o tipo de semente, condições climáticas e intimamente com o estágio de maturação (MARCOS et al., 1999; TSAI et al., 1970), devendo ser investigadas, com umidade variando de 70 a $80 \%$, para melhor recomendação ao produtor e aceitação do consumidor.

Os carboidratos são os constituintes bioquímicos mais abundantes nos vegetais, chegando a representar 50 a $80 \%$ do peso seco total destes. Eles são importantes fontes de energia e compõem a parte estrutural das células (KAYS, 1991). Tsai et al. (1970) avaliaram a variação de componentes composicionais no milho normal entre o $8^{\circ} \mathrm{e}$ o $28^{\circ}$ dia após a polinização e observaram predominância de açúcares redutores entre o $8^{\circ}$ e o $10^{\circ}$. Ao final do período de avaliação eles representam um pouco mais de $1 \%$ dos carboidratos totais. No milho normal há uma relação entre umidade, açúcares redutores, sacarose, amido e peso seco total durante o desenvolvimento do grão, isto é, a umidade decresce continuamente, enquanto o amido aumenta. Observações semelhantes foram verificadas por Creech (1965) que obteve correlações negativas entre o teor de açúcares totais, açúcares redutores e sacarose com a matéria seca e o amido, indicando que os açúcares são precursores do amido. No milho normal, Creech (1968) descreve que os açúcares totais aumentam até o $15^{\circ}$ dia após a polinização e diminuem durante o amadurecimento; os açúcares redutores estão presentes em maior quantidade nos primeiros estádios de maturação, diminuindo com o amadurecimento, já a sacarose aumenta rapidamente até o $15^{\circ}$ dia após a polinização, diminuindo lentamente a partir daí e os polissacarídeos totais aumentam durante todo o amadurecimento, os valores obtidos no $28^{\circ}$ dia após a polinização são semelhantes aos dos grãos maduros.

Avaliando genótipos de milho doce, Evensen \& Boyer (1986) observaram teores de amido variando entre 43,7 e $81 \mathrm{mg} / \mathrm{gMF}$, em espigas colhidas com umidade variando entre 75 e $80 \%$. Dessa forma, é desejável que a colheita seja realizada quando grande parte do amido não tenha sido acumulada, pois o sabor adocicado característico do produto fresco se deve à presença de açúcares livres nos grãos. Desta maneira, quanto menor a concentração de amido, maior a palatabilidade do produto, porém a proporção ideal entre açúcares e amido depende basicamente do tipo de preparação a que as espigas se destinam (MATOS et al., 2000; PARENTONI et al., 1990).

A composição química do milho também difere entre os genótipos como observado em milho doce (PEREIRA, 1987) e Nutrimaiz (SILVA et al., 1978). Deve-se, contudo avaliar cultivares especialmente para o consumo de milho "in natura", pois ainda é grande o número de agricultores que vêm utilizando, para consumo verde, as mesmas cultivares destinados à produção de grãos (PEREIRA FILHO et al., 2003). Atualmente, a recomendação de cultivares de milho apropriada para consumo no estádio verde tem motivado o estudo de seus atributos químicos, o que pode facilitar a escolha de cultivares pelos produtores.

Assim, o objetivo desse trabalho foi comparar a composição dos grãos verdes de milho das cultivares AL25, Dow270, CO32, AG4051, P3232, UFVM3, SHS4040, Dow170 e AG1051 em relação aos conteúdos de açúcares totais, açúcares redutores e amido, uma vez que estes influenciam diretamente o sabor, o aroma e a aceitação do consumidor.

As cultivares utilizadas neste estudo foram plantadas na fazenda experimental da EPAMIG no vale do Piranga, no município de Oratórios, MG no ano agrícola 2002/03. As cultivares AL25, Dow270,CO32, AG4051, P3232, UFVM3, SHS4040, Dow170 e AG1051 foram distribuídas no campo segundo o delineamento blocos casualizados com três repetições. A unidade experimental constituiu-se de quatro fileiras de cinco metros, com espaçamento entre linhas de um metro. Foi realizado o desbaste para se obter um estande final de 25 plantas/ fileira, com uma população de 50.000 plantas/ha. A parcela útil foi as duas linhas centrais. $\mathrm{Na}$ adubação foram adicionados e 4L de esterco bovino curtido, 40g de termofosfato e $10 \mathrm{~g}$ de sulfato de potássio e na adubação de cobertura 4L de esterco de bovinos. As plantas também receberam via foliar o biofertilizante supermagro $5 \%(\mathrm{v} / \mathrm{v})$. Para controle de plantas daninhas realizou-se capina manual. Fez-se uso de irrigação suplementar para atender a demanda no período.

A colheita foi realizada quando o material atingiu o estagio leitoso e foi identificado por método empírico, quando o estilo-estiga se desprendia da espiga com facilidade ao arranque manual. Três espigas foram colhidas por parcela na ocasião da colheita e tiveram os grãos retirados na região central da espiga com faca de aço inox.

A dosagem dos açúcares solúveis totais foi realizada por meio das reações com antrona (HODGE \& HOFREITER, 1962) baseada na absorbância a 620nm; a dosagem de açúcares redutores foi determinada pelo método de Nelson (HODGE \& HOFREITER, 1962) e a absorbância foi determinada a $540 \mathrm{~nm}$. Do resíduo proveniente da extração de açúcares solúveis totais, foi feita a determinação do amido seguindo o mesmo método utilizado para quantificação de açúcares solúveis totais, sendo o resultado multiplicado pelo fator 0,9 . 
Os dados obtidos foram submetidos à análise de variância (teste $\mathrm{F} \leq 5 \%$ ) e as médias comparadas com o teste de Duncan, a 5\% de probabilidade.

Observa-se que ocorreram diferenças significativas para porcentagem de umidade, açúcares solúveis totais (AST), amido e para relação entre açúcares redutores e açúcares solúveis totais (AR/AST), mas não para açúcares redutores (AR) entre as nove cultivares avaliadas (Tabela 1).

A colheita de milho verde deve ser realizada quando os grãos estejam com umidade entre 70 e $80 \%$ (PEREIRA FILHO et al., 2003), porém para as cultivares avaliadas neste estudo a umidade no momento da colheita variou de 56 a $64 \%$, podendo ser explicado possivelmente pelo método empírico utilizado para determinar o ponto de colheita, o que pode ter proporcionado a colheita fora da época ideal. Sugerindo que este método de ser utilizado com cuidado pelos produtores, com o intuito de obter espigas com adequada porcentagem de umidade e um produto final com qualidade. As cultivares colhidas com maior umidade foram o Dow270 (64\%) e CO32(63\%) enquanto o AG4051 apresentou teor de umidade $(56 \%)$. As cultivares foram colhidos com umidade média de $61 \%$.

Não foi detectada diferença entre as cultivares avaliadas quanto ao teor de AR, convém enfatizar que estes foram corrigidos para a umidade, que apresentou desuniformidade no momento da colheita (Tabela 1). O conteúdo de AST representa os açúcares estruturais presentes nos grãos como também os açúcares redutores, responsáveis pelo sabor adoçicado, característico do produto fresco. A cultivar CO32 apresentou-se superior as demais quanto ao conteúdo de AST. Todavia não podemos afirmar que esta cultivar é o melhor, pois, deve-se avaliar também a relação AR/AST, principalmente porque as cultivares não foram diferenciadas pelo teor de AR. Assim, a porcentagem de AR em relação aos AST evidenciadas na Tabela 1, trará melhores informações sobre as cultivares. A maior relação foi observada para as cultivares P3232 e AG4051 com 76 e $78 \%$, respectivamente, sendo possuidores de características desejáveis ao consumo "in natura”. Segundo Creech (1968) o teor de açúcares redutores é maior nos primeiros estágios de amadurecimento. Além disso, o avanço da maturação promove a conversão de maior parte dos açúcares livres em amido (KAYS, 1991). Com isso, a alta relação apresentada por ambos, P3232 e AG4051 pode indicar o estádio de maturação próximo do ideal.

Com relação à composição de amido, a cultivar $\mathrm{CO} 32$ apresentou teores altos (Tabela 1), indicando a evolução da maturação nesta cultivar, de forma que as reações de transformações de açúcares pudessem ser observadas. Este deve ser indicado para o preparo de pratos típicos como curau, mingau e pamonha, dada à necessidade de amido para a sua execução. As cultivares A125, Dow170, AG1051 e AG4051 apresentaram os menores teores de amido, sendo por isso indicada para consumo em saladas, assado ou cozido, pois os grãos necessitam estarem mais novos, ou seja, com menores teores de amido (MATOS et al., 2000).

Tabela 1 - Médias de umidade, açúcares solúveis totais ${ }^{1}$ (AST), açúcares redutores ${ }^{1}(\mathrm{AR})$, amido ${ }^{1}$ e relação AR/AST, obtidas dos grãos verdes das nove cultivares avaliadas.

\begin{tabular}{|c|c|c|c|c|c|c|c|c|c|c|}
\hline \multirow{2}{*}{$\begin{array}{l}\text { Cultivares } \\
\text { Dow270 }\end{array}$} & \multicolumn{2}{|c|}{ Umidade (\%) } & \multicolumn{2}{|c|}{$\begin{array}{c}\text { AR } \\
\left(\mathrm{mg} / \mathrm{g} \mathrm{MS}{ }^{3}\right)\end{array}$} & \multicolumn{2}{|c|}{$\begin{array}{c}\text { AST } \\
(\mathrm{mg} / \mathrm{g} \mathrm{MS})\end{array}$} & \multicolumn{2}{|c|}{$\begin{array}{c}\text { Amido } \\
(\mathrm{mg} / \mathrm{g} \text { MS })\end{array}$} & \multicolumn{2}{|c|}{ AR/AST $(\%)$} \\
\hline & 64,07 & $\mathrm{a}$ & 6,30 & $\mathrm{a}$ & 9,05 & $\mathrm{ab}$ & 19,73 & $\mathrm{ab}$ & 69,47 & $\mathrm{ab}$ \\
\hline $\mathrm{CO} 32$ & 63,3 & $\mathrm{a}$ & 5,41 & $\mathrm{a}$ & 10,26 & $\mathrm{a}$ & 23,13 & $\mathrm{a}$ & 52,38 & $a b$ \\
\hline UFVM3 & 61,93 & $a b$ & 5,36 & $\mathrm{a}$ & 8,46 & $a b$ & 20,51 & $a b$ & 65,01 & $a b$ \\
\hline AL25 & 61,9 & $a b$ & 4,12 & $\mathrm{a}$ & 9,69 & $a b$ & 17,28 & $\mathrm{~b}$ & 42,61 & $\mathrm{~b}$ \\
\hline Dow170 & 61,87 & $\mathrm{ab}$ & 5,62 & $\mathrm{a}$ & 7,97 & $\mathrm{~b}$ & 18,90 & $\mathrm{~b}$ & 69,86 & $a b$ \\
\hline SHS4040 & 60,87 & $\mathrm{ab}$ & 6,13 & $\mathrm{a}$ & 9,65 & $a b$ & 21,84 & $a b$ & 63,69 & $a b$ \\
\hline P3232 & 60,47 & $a b$ & 6,17 & $\mathrm{a}$ & 8,19 & $a b$ & 19,16 & $\mathrm{ab}$ & 76,01 & $\mathrm{a}$ \\
\hline AG1051 & 58,6 & $\mathrm{ab}$ & 4,50 & $\mathrm{a}$ & 7,63 & $\mathrm{~b}$ & 17,55 & $\mathrm{~b}$ & 59,44 & $a b$ \\
\hline AG4051 & 56,73 & $\mathrm{~b}$ & 6,24 & $\mathrm{a}$ & 7,93 & $\mathrm{~b}$ & 16,90 & $\mathrm{~b}$ & 78,74 & $\mathrm{a}$ \\
\hline $\mathrm{CV}(\%)$ & \multicolumn{2}{|c|}{5,23} & \multicolumn{2}{|c|}{24,74} & \multicolumn{2}{|c|}{12,33} & & 33 & \multicolumn{2}{|c|}{24,71} \\
\hline
\end{tabular}

${ }^{1}$ Dados originais foram transformados para $\sqrt{X}$ para análise estatística

${ }^{2}$ Médias seguidas da mesma letra, na coluna, não diferem significativamente, pelo teste de Duncan a 5\%.

${ }^{3} \mathrm{MS}=$ Matéria Seca 
Estes resultados permitem inferir que a época de colheita devesse ser antecipada. Para Kays (1991) e Pereira Filho et al. (2003) a época de colheita para milho verde deve ser acompanhada pela redução da umidade, próxima a $70-80 \%$, pois o avanço na maturação pode reduzir as qualidades pós-colheita dos grãos de milho verde, mesmo naquelas cultivares recomendadas para esta finalidade.

Nas condições experimentais avaliadas os dados indicam que a época de colheita deve ser antecipada, a fim de se obter um produto final de alta qualidade pós-colheita. E principalmente, o método adotado para identificação do ponto de colheita foi ineficiente, uma vez que os teores de umidade variaram muito, o que torna esses resultados discutíveis.

As cultivares P3232 e AG4051 apresentaram característica desejável, como alta relação entre açúcares redutores e açúcares solúveis totais no momento da colheita, tornando-os adequados para esta finalidade.

\section{AGRADECIMENTOS}

À FAPEMIG (Fundação de Amparo a Pesquisa do Estado de Minas Gerais) pelo financiamento do projeto.

\section{REFERÊNCIAS BIBLIOGRÁFICAS}

CREECH, R. G. Genetic control of carbohydrate synthesis in maize endosperm. Genetics, Maryland, v. 52, n. 4, p. 1175-1185, Dec. 1965.

CREECH, R. G. Carbohydrate synthesis in maize. In: NORMAN, A. G. Advances in Agronomy. New York: Academic, 1968. p. 275-289.

EVENSEN, K. B.; BOYER, C. D. Carbohydrate composition and sensory quality of fresh and stored sweet corn. Journal American Society for Horticultural Science, Mount Vernon, v. 111, n. 5, p. 734-738, Sept./Nov. 1986.

FAO. Statistical database. Rome, 2002. Disponível em: < h t t p : / / f a o s t a t . f a o . org / f a o s t a t / collections?subset=agriculture $>$. Acesso em: 24 set. 2005.

HODGE, J. E.; HOFREITER, B. T. Determination of reducing sugars and carbohydrates. In: WHISTLER, J. E.;
WOLFROM, M. L. Methods in carbohydrate chemistry. New York: Academic, 1962. p. 380-394.

INSTITUTO BRASILEIRO DE GEOGRAFIA E ESTATÍSTICA. Censo agropecuário. Rio de Janeiro, 1996. Disponível em: <http://www.sidra.ibge.gov.br/bda/tabela/ >. Acesso em: 24 set. 2005.

KAYS, E. J. Postharvest physiology of perishable plant products. New York: V. N. Reinhold, 1991. 532 p.

MARCOS, S. K.; HONÓRIO, S. L.; JORGE, J. T.; AVELAR, J. A. A. Influência do resfriamento do ambiente de armazenamento e da embalagem sobre o comportamento pós-colheita do milho verde. Revista Brasileira de Engenharia Agrícola e Ambiental, Campina Grande, v. 3, n. 1, p. 41-44, jan./abr. 1999.

MATOS, M. J. L. F.; TAVARES, S. A.; SANTOS, F. F.; MELO, M. F.; LANA, M. M. Milho verde. Correio Brasiliense, Brasília, abr. 2000.

PARENTONI, S. N.; GAMA, E. E. G.; MAGNAVACA, R.; REIFSCHNEIDER, F. J. B.; BOAS, G. L. V. Milho doce. Informe Agropecuário, Belo Horizonte, v. 14, n. 165, p. 1722, 1990.

PEREIRA, A. S. Composição, avaliação organoléptica e padrão de qualidade de cultivares de milho doce. Horticultura Brasileira, Brasília, v. 5, n. 2, p. 22-24, nov. 1987.

PEREIRA FILHO, I. A.; CRUZ, J. C.; GAMA, E. E. G. Cultivares para consumo verde. In: PEREIRA FILHO, I. A. (Ed.). O Cultivo do milho-verde. Brasília, DF: Embrapa Informações Tecnológicas, 2003. p. 17-30.

SILVA, W. J.; TEIXEIRA, J. P. F.; ARRUDA, P.; LOVATO, M. B. Nutrimaiz, a tropical sweet maize cultivar of high nutritional value. Maydica, Bergamo, v. 23, n. 3, p. 129-134, jan./mar. 1978.

TSAI, C. Y.; SALAMINI, F.; NELSON, O. E. Enzymes of carbohydrate metabolism in developing endosperm of maize. Plant Physiology, Bethesda, v. 46, n. 2, p. 299-336, July/Sept. 1970. 